\title{
SYNTHESIS AND CRYSTAL STRUCTURE ANALYSIS OF A NEW CHALCONE DERIVATIVE OF APOCYNIN
}

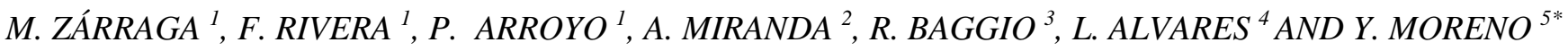 \\ ${ }^{I}$ Universidad de Concepción, Depto. Química Orgánica, Edmundo Larenas 234. \\ ${ }^{2}$ Dpto. Química, Facultad de Ciencias Básicas, Universidad Metropolitana de Ciencias de la Educación, Avda. José Pedro Alessandri 774, Santiago, Chile. \\ ${ }^{3}$ Comisión Nacional de Energía Atómica, Gerencia de Investigación y Aplicaciones, Centro Atómico Constituyentes, Buenos Aires, Argentina. \\ ${ }^{4}$ Departamento de Química, Universidad Técnica Federico Santa María, Valparaiso, Chile. \\ ${ }^{5}$ Facultad de Ciencias Básicas, Universidad Santo Tomás, Limonares 190, Viña del Mar, Chile.
}

\begin{abstract}
In the present report we present the synthesis and structural analysis of a chalcone derivative of Apocynin, 1-(4-hydroxy-3-methoxyphenyl)-3-(4-nitrophenyl)-2propenone. The most characteristic feature of its molecular structure is its near-planarity, allowing molecules to be stacked in columns, at graphite intermolecular distances to each other and connected by a large variety of weak intermolecular interactions. The molecule presents structural analogies to related ones with significant pharmacological properties (e.g., Apocynin).
\end{abstract}

Keywords: Apocynin derivative, chalcone, crystal structure.

\section{INTRODUCTION}

Apocynin, also known as acetovanillone (Scheme 1, (a)), is a natural organic compound structurally related to vanillin. It has been isolated from a variety of plant sources and is derivatives are being studied for their variety of pharmacological properties. In particular, some of them have shown anti-cancer properties (viz., by inhibiting the migration of breast cancer cells, etc. ${ }^{1}$ ), something which suggests promising new routes for the development of novel anticancer therapeutics.

On the other hand chalcones $(\alpha, \beta$-unsaturated carbonyl compounds with a common chemical scaffold of 1,3-diaryl-2-propen-1-one, Scheme 1, (b)) may play important roles against a diversity of human diseases, acting as antiinflammatory ${ }^{2}$, antileishmanial ${ }^{3}$, antimalarial ${ }^{4}$, antifungal ${ }^{5}$, antioxidant ${ }^{6}$, anticancer ${ }^{7}$ and antibacterial agents ${ }^{8,9}$. Natural and synthetic chalcones have been reported as effective inhibitors of induced nociception ${ }^{9}$ and the Transient Receptor Potential Vanilloid 1 receiver (TRPV1, formerly known as the Vanilloid Receptor VR1) modulation ${ }^{10}$. (a)<smiles>COc1cc(C(C)=O)ccc1O</smiles>

(b)<smiles>O=C(/C=C/c1ccccc1)C1CCCCC1</smiles>

Chalcone scaffold (c)

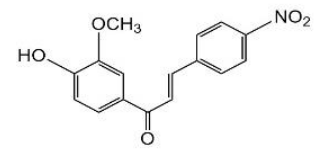

(I)
Scheme 1.

In this regard, the past ten years have seen the emergence of specific small molecule antagonists targeting receptors on sensory neurons that detect painful stimuli. Among these new therapeutic targets, TRPV1 has attracted most of the attention ${ }^{2}$. The receptor is probably still best recognized as the receptor for Capsaicin (Scheme 2, A), which is responsible for the piquancy of hot chili peppers ${ }^{11}$. The search of new modulating ligands of TRPV1 receptors, agonists or antagonists, constitutes a strategy in the development of new drugs for the pain treatment.



Scheme 2.
Structural specific requirements have been described for this type of compounds, many of them based on the natural structure of Capsaicin, the first natural ligand known for this receptor ${ }^{11}$.

We have formerly designed and synthesized a number of Capsaicin analogous compounds with increased conformational restrictions about the amide link (Scheme 2, A, zones I, II, III) with the heterocycle incorporation, like azoles or a chalcones (Scheme 2, B,C,D).

Apocinine-derived Chalcones preserve the structure of the ring and the Capsaicin substitutes, and the rotation around the conjugated carbonyl group is restricted. It is worth noting that the synthesis of this structure may lead to the formation of both isomers (cis-trans), being important the characterization of the trans structure coming out of this synthesis.

In the present report we present the synthesis and structural analysis of a chalcone derivative of Apocynin, 1-(4-hydroxy-3-methoxyphenyl)-3-(4nitrophenyl)-2-propenone (hereinafter (I), Scheme 1, (c)).

\section{EXPERIMENTAL}

\section{Synthesis}

Compound (I) was obtained with a moderately successful outcome (44.6\% yield) through Claisen-Schmidt condensation, the main method for the synthesis of chalcones in the presence of an aqueous alkaline base ${ }^{12}$.

To a mixture of 4-nitrophenylraldehyde $(0.01 \mathrm{~mol})$ and 3-methoxy-4hydroxyphenyletanone (Apocynine) $(0.01 \mathrm{~mol})$ in ethanol $(50 \mathrm{~mL}), 1.0 \mathrm{~mL}$ of $20 \%$ sodium hydroxide solution was added and stirred at $0-3^{\circ} \mathrm{C}$ for $5 \mathrm{~h}$. The precipitate formed was collected by filtration and purified by recrystallization from ethanol. Single crystals were grown from absolute ethanol by slow evaporation. Scheme 3 sketches this synthetic procedure.

\section{FTIR, ${ }^{1} \mathrm{H} /{ }^{13} \mathrm{C}$ RMN}

As supplementary materials, 1H / 13C NMR and FTIR spectroscopic data are provided.

FTIR spectra were performed on a Nicollet-FT-IR (Magna 550), the samples were diluted in $\mathrm{KBr}$ salt. ${ }^{1} \mathrm{H}$ NMR.and ${ }^{13} \mathrm{C}$ NMR Nuclear Magnetic Resonance spectra were performed on a Bruker Ascend-400 [MHz] equipment. For ${ }^{1} \mathrm{H}$ NMR was used DMSO solvent, 6d (DMSO-2.5199 ppm).

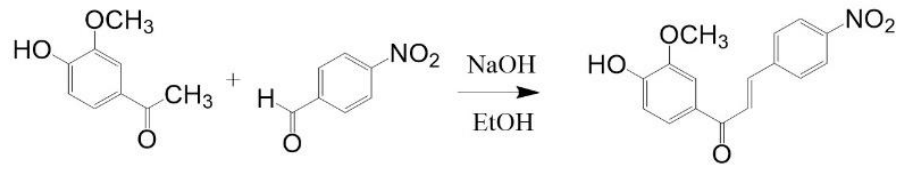

Scheme 3. 


\section{Crystal Structure Determination}

Single crystal diffraction patterns were recorded with a Bruker SMART AXS CCD diffractometer with graphite-monochromated Mo Ka radiation $(\lambda=0.71073 \AA)$ and a semi-empirical absorption correction based on symmetry equivalent reflections was applied. A total of 43905 reflections were collected, providing a unique data set of 4071 reflections (Rint $=0.093$ ) of which 2827 had I $>2 \sigma(\mathrm{I})$. The structure was solved by direct methods with SHELXS ${ }^{13}$ and refined by the full-matrix least-squares based on $\mathrm{F}^{2}$ using SHELXL-2014 ${ }^{14}$. Structure analysis was performed with the aid of the PLATON software ${ }^{15}$ Figures were produced with XP in the SHELXTL crystallographic package ${ }^{13}$.

Non-hydrogen atoms were located from an E-map and refined in anisotropic approximation. The hydrogen atoms were originally detected in difference maps, and further idealized and allowed to ride on the corresponding non-H atoms, with $\mathrm{C}-\mathrm{H}=0.96 \AA$ and $\mathrm{Uiso}(\mathrm{H})=1.5 \mathrm{Ueq}$ of the attached $\mathrm{C}$ atoms for methyl groups and $\mathrm{C}-\mathrm{H}=0.93 \AA$ or $\mathrm{O}-\mathrm{H}=0.82 \AA$ and $\operatorname{Uiso}(\mathrm{H})=1.2$ Ueq for the remaining ones.

Crystallographic data for (I) has been deposited at the CCDC under code CCDC2003556. These data can be obtained free of charge via the CCDC retrieval website http://www.ccdc.cam.ac.uk/conts/retrieving.html.

\section{RESULTS AND DISCUSSION}

The synthesis, by Claisen-Schmidt condensation of this Apocynin-derived chalcone, with nitro group, was obtained in a $44.6 \%$ yield.

The IR spectrum indicates the presence of a hydroxyl group, $v=3279.1 \mathrm{~cm}^{-1}$, and a conjugated carbonyl group, $v=1651.4 \mathrm{~cm}^{-1}$, as well as the $\mathrm{CH}$ tension vibration of $\mathrm{sp}^{2}$ carbons of alkene double bond, $v=3100 \mathrm{~cm}^{-1}$; signals from the nitro group at $v=1511.2$ and $v=1350 \mathrm{~cm}^{-1}$ are also observed.

The ${ }^{1} \mathrm{H}$ nuclear magnetic resonance spectrum shows a singlet at $3.99 \mathrm{ppm}$, which corresponds to an integration of three hydrogens due to the methoxy group.

The chemical shift of the double bond hydrogens are found at $\delta 8.13 \mathrm{ppm}(1 \mathrm{H}$, $\mathrm{d}, \mathrm{J}=15.6 \mathrm{~Hz})$ and $7.77 \mathrm{ppm}(1 \mathrm{H}, \mathrm{d}, 15.6 \mathrm{~Hz})$; the value of its coupling constant, $15.6 \mathrm{~Hz}$, is indication of a trans orientation.

Phenyl hydrogens, from the p-nitro phenyl group, are highly displaced towards the low field; correspond to two doublets at $\delta 8.28$ and $8.16 \mathrm{ppm}$ respectively. Its integration is consistent with two hydrogens each and its coupling constant is $8.6 \mathrm{~Hz}$; in contrast, the hydrogens on the aromatic ring of Apocynin are presented at $7.85 \mathrm{ppm}(1 \mathrm{H}, \mathrm{dd}, \mathrm{J}=8.32,1.28 \mathrm{~Hz}) ; 7.65 \mathrm{ppm}(1 \mathrm{H}, \mathrm{d}, \mathrm{J}=1.28 \mathrm{~Hz})$ and $6.95 \mathrm{ppm}(1 \mathrm{H}, \mathrm{d}, 8.32 \mathrm{~Hz})$.

Table 1. Crystal data and structure refinement for $\mathbf{I}$.

\begin{tabular}{|c|c|}
\hline Empirical formula & $\mathrm{C}_{16} \mathrm{H}_{13} \mathrm{NO}_{5}$ \\
\hline Formula weight & 299.27 \\
\hline Temperature /K & $296(2)$ \\
\hline Crystal system & monoclinic \\
\hline Space group & $\mathrm{P} 2_{1} / \mathrm{c}$ \\
\hline $\mathrm{a} / \AA$ & $8.451(4)$ \\
\hline $\mathrm{b} / \AA ̊ \AA$ & $12.739(5)$ \\
\hline $\mathrm{c} / \AA ̊ \AA$ & $13.308(5)$ \\
\hline$\beta /{ }^{\circ}$ & $101.894(5)$ \\
\hline Volume $/ \AA^{3}$ & $1401.9(10)$ \\
\hline $\mathrm{Z}, \mathrm{Z}^{\prime}$ & 4,1 \\
\hline$\rho_{\text {calc }} \mathrm{g} / \mathrm{cm}^{3}$ & 1.418 \\
\hline$\mu / \mathrm{mm}^{-1}$ & 0.107 \\
\hline $\mathrm{F}(000)$ & 624 \\
\hline Radiation & $\operatorname{MoK} \alpha(\lambda=0.71073 \AA)$ \\
\hline $2 \Theta$ range for data collection $/^{\circ}$ & 4.472 to 60.81 \\
\hline Index ranges & $-11 \leq \mathrm{h} \leq 11,-17 \leq \mathrm{k} \leq 18,-18 \leq 1 \leq 18$ \\
\hline Reflections collected & 43905 \\
\hline Independent reflections & $4071\left[R_{\text {int }}=0.0934, R_{\text {sigma }}=0.0478\right]$ \\
\hline Data/restraints/parameters & $4071 / 0 / 199$ \\
\hline Goodness-of-fit on $\mathrm{F}^{2}$ & 1.087 \\
\hline Final $\mathrm{R}$ indexes $[\mathrm{I}>=2 \sigma(\mathrm{I})]$ & $\mathrm{R}_{1}=0.074, \mathrm{wR}_{2}=0.2201$ \\
\hline Final $\mathrm{R}$ indexes [all data] & $\mathrm{R}_{1}=0.0972, \mathrm{wR}_{2}=0.2389$ \\
\hline Largest diff. peak/hole / e $\AA^{-3}$ & $0.44 /-0.51$ \\
\hline
\end{tabular}

Compound (I) crystallizes in the monoclinic space group P21/c ( $Z=4)$ with one single molecule in the asymmetric unit $\left(Z^{\prime}=1\right)$. Table 1 presents some data collection and refinement parameters while Fig.1 displays an ellipsoid plot of the molecule drawn at a 50\% probability level. Bond distances and angles are unexceptional, and will not be discussed in detail.

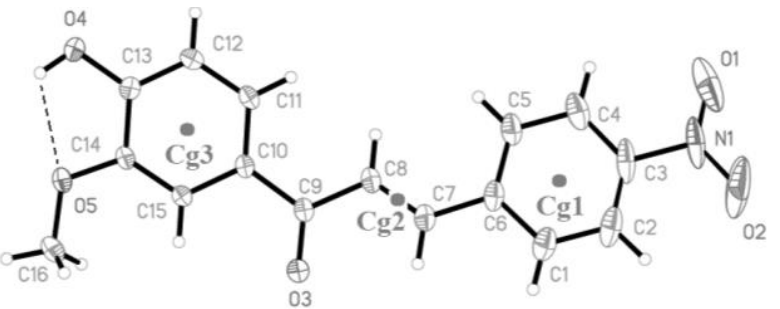

Figure 1. RX molecular diagram with displacement ellipsoids drawn at a 50\% probability level, showing atom and centroid labeling. In broken line, intramolecular H-bond.

The molecule is basically planar, with a mean overall departure from its best plane of $0.077 \AA$. This fact can also be disclosed by the analysis of torsion angles, most of them below $3^{\circ}$ in absolute value. Only those around the $\mathrm{C} 7=\mathrm{C} 8$ and $\mathrm{C} 8$ C9 bonds appear a bit larger, with values slightly above $5^{\circ}$. The cumulative effect of these small distortions along the propenone chain end up with a dihedral angle between terminal phenyl rings of $9.02(10)^{\circ}$.

In order to compare this planar geometry of (I) with those of related structures we made a search in the CSD for reported chalcones with a similar (unsubstituted) propenone core bridging two terminal phenyl rings. We found out that there were about sixty of those structures, with a phen-phen dihedral angle span of $2.5-87.5^{\circ}$. Thus, (I) appears to be slightly lent towards the planar side of the lot.

Even if not strong, intermolecular interactions are of a varied nature $(\pi \ldots \pi, \mathrm{H}-$ bonding, anion....anion). The most significant for the crystal packing are given in Table 2, with an identification code in the leading column, provided for easy of reference.

Table 2. Non-covalent interactions in (I).

\begin{tabular}{|c|c|c|c|}
\hline \multicolumn{5}{|c|}{$\boldsymbol{\pi} \boldsymbol{\pi}$ contacts } \\
\hline Code & $\mathbf{C g} . . . \mathrm{Cg}$ & $\mathbf{d}(\boldsymbol{\pi} \boldsymbol{\pi})(\AA)$ & $\mathbf{C g}-\mathbf{C g} \mathbf{g}_{\text {perp }}\left({ }^{\circ}\right)$ \\
\hline$\# 1$ & $\mathrm{Cg} 2 \mathrm{Cg} 2^{\mathrm{i}}$ & $4.006(3)$ & $13.3(3)^{\circ}$ \\
\hline
\end{tabular}

\begin{tabular}{|c|c|c|c|c|c|}
\hline \multicolumn{6}{|c|}{ H-bonding interactions } \\
\hline Code & $\mathbf{D}-\mathbf{H} \cdots \mathbf{A}$ & $\mathbf{D}-\mathbf{H}(\AA)$ & $\mathbf{H} \cdots \mathbf{A}(\AA)$ & $\mathbf{D} \cdots \mathbf{A}(\AA)$ & $\mathbf{D}-\mathbf{H} \cdots \mathbf{A}\left({ }^{\circ}\right)$ \\
\hline$\# 2$ & $\mathrm{C} 16-\mathrm{H} 16 \mathrm{C} \ldots \mathrm{Cg} 1^{\mathrm{ii}}$ & 0.95 & 2.73 & $3.484(3)$ & 136 \\
\hline$\# 3$ & $\mathrm{O} 4-\mathrm{H} 4 \mathrm{O} \ldots \mathrm{O}^{\mathrm{iii}}$ & 0.82 & 2.03 & $2.747(3)$ & 146 \\
\hline \#4 & $\mathrm{C} 15-\mathrm{H} 15 \ldots \mathrm{O} 4^{\mathrm{iv}}$ & 0.93 & 2.42 & $3.246(2)$ & 148 \\
\hline \#5 & $\mathrm{C} 11-\mathrm{H} 11 \ldots \mathrm{O} 2^{\mathrm{v}}$ & 0.93 & 2.47 & $3.307(4)$ & 151 \\
\hline
\end{tabular}

\begin{tabular}{|c|c|c|}
\hline \multicolumn{3}{|c|}{ Anion...Anioncontacts } \\
\hline Code & An...An & d(An...An) $(\AA)$ \\
\hline$\# 6$ & ${\mathrm{O} 1 . . . O 1^{\text {vi }}}$ & $3.2276(16)$ \\
\hline
\end{tabular}

Symmetrycodes: (i), 1-x, 1-y, 1-z, (ii), 2-x, 1-y, 1-z, (iii), 2-x, -1-y, -z, (iv) 2$\mathrm{x},-\mathrm{y},-\mathrm{z},(\mathrm{v}), 1-\mathrm{x},-1-\mathrm{y}, 1-\mathrm{z}$, (vi) 1-x, 1-y, 2-z.

$\mathrm{Cg}$ codes as in Fig. 3

The quasi planar molecules stack along [100], in a slanted fashion (with their mean plane at $36.5^{\circ}$ to the $\boldsymbol{a}$ axis) to form columns mainly held by interactions between their delocalized $\pi$ systems. Fig. 2 shows the way in which this is achieved, with parallel molecules related by the two different inversion centres in the crystal $(A, B)$, leading to alternating graphitic spacings of $d_{A}: 3,35(2), d_{B}$ : $3.45(2) \AA$. Among the delocalized interactions stabilizing these columns there are a few, localized ones, e.g. contacts \#1 and \#2 in Table 2 which are shown in Fig.2. 


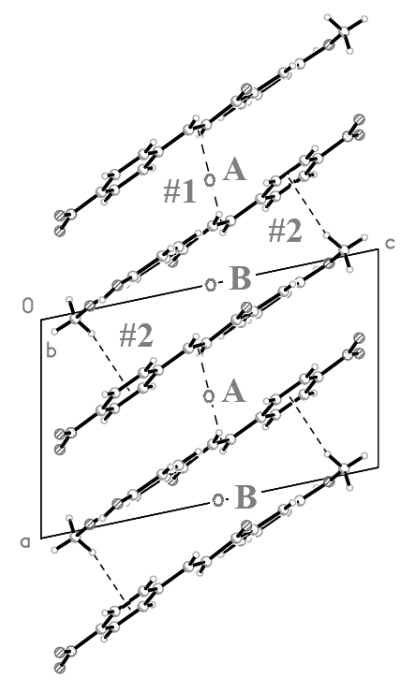

Figure 2. Columnar array in (I), showing the alternating stacking sequence of molecules running along [100]. A and B denote the different inversion centres along the column.

Being columns perpendicular to the unique axis $\boldsymbol{b}$, the remaining symmetry operations $(2$, c) generate related columns also parallel to [100] and thus the packing shown in Fig. 3 is built up. Neigbouring columns are now linked by interactions \#3 to \#6, which provide for a strong stabilizing effect, as disclosed by the rather large Kitaigorodskii Packing Index ${ }^{16}$ of 0.72 , as calculated by Platon ${ }^{15}$ Usual values for organic structures lay in the range $0.68-0.69$.

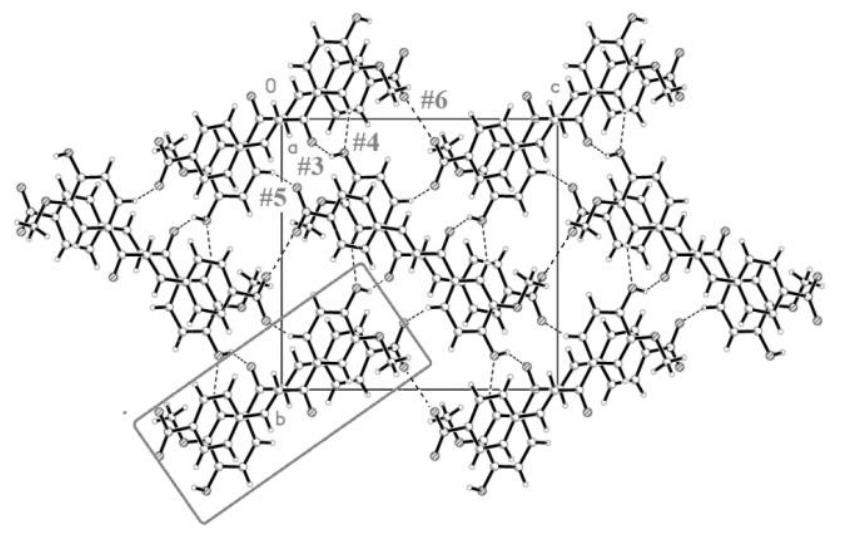

Figure 3. Crystal packing of (I), projected along a, showing the interaction between parallel columns (drawn alongside). One of the columns has been highlighted, for clarity.

\section{CONCLUSION}

1-(4-hydroxy-3-methoxyphenyl)-3-(4-nitrophenyl)-2-propenone (I) was synthesized by the Claisen-Schmidt method, with a moderately successful outcome ( $44.6 \%$ yield). The most characteristic feature of its molecular structure is its near-planarity, allowing molecules to be stacked in columns, at graphite intermolecular distances to each other and connected by a large variety of weak intermolecular interactions.

The molecule presents structural analogies to related ones with significant pharmacological properties (e.g., Apocynin). The search of similar bio-activities in (I) (something far from our present capabilities) would probably constitute a natural continuation of the present synthetic and structural analysis.

\section{REFERENCES}

1. Robert F Klees 1, Paul C De Marco, Roman M Salasznyk, Disha Ahuja, Michael Hogg, Sylvain Antoniotti, Lakshmi Kamath, Jonathan S Dordick, George E Plopper. J Biomed Biotechnol, 2, 87246 (2006).

2. Vogel, S., Barbic, M., JurgenlIemk, G. and Heilmann, J. European Journal of Medicinal Chemistry. 45, 2206-2213 (2010).
3. Aponte, J. C., Castillo, D., Estevez, Y., Gonzalez, G., Arevalo, J., Hammond, G. B. and Sauvain, M. Chemistry Letters. 20, 100-103, (2010).

4. Tadigoppula, N., Korthikunta, V., Gupta, S., Kancharla, P., Khaliq, T., Soni, A., Srivastava, R. K., Srivastava, K., Puri, S. K. and Raju, K. S. R. Journal of Medicinal Chemistry. 56, 3145 (2012).

5. Ameta, K., Kumar, B. and Rathore, N. S. Journal of Chemistry. 8: 665-670 (2011).

6. Doan, T. N. and Tran, D. T. Pharmacology and Pharmacy. 2: 282-288 (2011).

7. Syam, S., Abdelwahab, S. I., Al-mamary, M. A. and Mohan, S. Molecules. 17: 6179-6195 (2012).

8. Asiri, A. M. and Khan, S. A. Molecules. 16: 523-531 (2011).

9. Nur Izzati Ismail,Lee Ming-Tatt,Nordin Lajis,Muhammad Nadeem Akhtar,Ahmad Akira,Enoch Kumar Perimal,Daud Ahmad Israf andMohd Roslan Sulaiman. Molecules , 21(8), 1077 (2016).

10. Benso $\mathrm{B}^{1}$, Bustos $\mathrm{D}^{2}$, Zarraga $\mathrm{MO}^{3}$, Gonzalez $\mathrm{W}^{4}$, Caballero $\mathrm{J}^{2}$, Brauchi $S^{5}$.Int J Biochem Cell Biol. 112,18-23 (2019).

11. Mark F McCarty, James J DiNicolantonio, and James H O'Keefe. Open Heart. 2(1): e000262 (2015).

12. Crystallography Reports, volume 62, pages1157-1159(2017)

13. Sheldrick G.M. ActaCrystallogr. A64 pp. 112-122 (2008).

14. Sheldrick, G.M. ActaCrystallogr. C71 pp 3-8 (2015).

15. Spek, A.L. ActaCrystallogr. D65 pp. 148-155 (2009).

16. Kitaigorodskii, A. I. In Organic Chemical Crystallography. New York: Consultants Bureau (1961). 